\title{
Fixed Prices versus Predetermined Prices and the Equilibrium Probability of Price
}

\section{Adjustment}

\author{
James Yetman \\ University of Hong Kong*
}

February 14, 2003

\begin{abstract}
Elsewhere, papers comparing fixed prices with predetermined prices have assumed that the frequency of re-setting price contracts is equal in either case. This note demonstrates that in equilibrium, the frequency of re-setting price contracts is greater with fixed prices than predetermined prices.
\end{abstract}

JEL Classification E31, E32

Keywords: fixed prices, predetermined prices, money shocks

* School of Economics and Finance, University of Hong Kong, Pokfulam Road, Hong Kong, Phone (852) 2857-8506, Fax (852) 2548-1152, Email jyetman@econ.hku.hk. The author thanks Mick Devereux, Michael Woodford, and an anonymous referee for their comments. Any remaining errors are the author's sole responsibility. 


\section{Section 1. Introduction}

In standard sticky-price models, firms face menu costs, and therefore set a fixed price (FP) for all periods of a price contract. Recent papers by Devereux and Yetman (2001) and Mankiw and Reis (2001) have introduced an alternative framework in which prices are predetermined (PP), but a price contract may specify different prices for each future period, as in Fischer (1977). This alternative is consistent with the idea that sticky prices stem from the cost of drawing up a contract, rather than menu costs. ${ }^{1}$ In both frameworks, firms face a constant, exogenous probability of readjusting their price contracts each period, as in Calvo (1983).

In this existing literature, the probability of setting a new price contract each period is exogenous, and common to both the FP and PP models. However, there is no intuitive rationale for why this should be the case. In this paper, the probability of readjusting price contracts each period is treated as endogenous as in Romer (1990) and Devereux and Yetman (2002). We show that the Nash equilibrium frequency of price adjustment is less with PP than FP, and the difference between them is increasing in the level of real rigidity.

The next section develops the model. Section 3 illustrates the results. A conclusion then follows.

\section{Section 2: A model of sticky prices}

The quantity theory equation is written in $\log$ terms as

$$
\text { (1) } y_{t}=m_{t}-p_{t} \text {, }
$$

\footnotetext{
${ }^{1}$ Mankiw and Ries (2001) refer to these as "Sticky Prices" and "Sticky Information" respectively.
} 
where $y_{t}$ is aggregate output and $m_{t}-p_{t}$ represents real balances. The nominal marginal cost facing each firm is

$$
w_{t}=p_{t}+v y_{t},
$$

where $v$ measures the elasticity of the real wage (marginal cost) to output. Therefore the desired price of any firm is just the marginal cost in any period (ignoring the constant mark-up term), and can be written as

$$
p_{t}^{*}=(1-v) p_{t}+v m_{t}
$$

The lower $v$ is, the less willing individual firms are to adjust their desired price, relative to the aggregate price level. This is the case where there is real rigidity [Ball and Romer (1990), Romer (1996)], or strategic complementarity [Woodford (2001)].

Consider the pricing decision of a representative firm. A firm that must set its price in advance experiences a loss in expected profits, relative to a situation where price adjustment is instantaneous, approximately equal to the squared deviation of the log price from the desired log price [Walsh (1998)]. Thus any firm $i$ faces an expected loss of

$$
L_{t}(i)=F+E_{t} \sum_{j=0}^{\infty}(\beta \kappa)^{j}\left(\hat{p}_{t+j, t}(i)-p_{t+j}^{*}\right)^{2}+\frac{1-\kappa}{\kappa} \sum_{j=1}^{\infty}(\beta \kappa)^{j} L_{t+j}(i)
$$

where $\beta$ is the discount factor, $F$ is the cost of updating a price contract, $\kappa$ is the probability that the firm does not change its price in any given period, and $\hat{p}_{t+j, t}(i)$ is the price set by firm $i$ in period $t$ for period $t+j$.

\section{Monetary process}

The money stock follows an AR(1) in first differences with drift (empirical support for this is provided later). Thus,

$$
m_{t}-m_{t-1}=\rho\left(m_{t-1}-m_{t-2}\right)+\bar{m}+u_{t}
$$


where $u_{t} \sim \operatorname{iid}\left(0, \sigma_{u}^{2}\right)$.

\section{Fixed Prices (FP)}

Suppose that changing a nominal price is costly. Then, when setting a price contract at time $t$, a firm will set a fixed nominal price that holds for the life of the contract (that is, $\left.\hat{p}_{t+j, t}(i)=\hat{p}_{t}(i) \forall j\right)$. The firm sets its price to minimize an expected loss of

$$
L_{t}(i)=E_{t} \sum_{j=0}^{\infty}(\beta \kappa)^{j}\left(\hat{p}_{t}(i)-p_{t+j}^{*}\right)^{2}
$$

or

$$
\hat{p}_{t}(i)=(1-\beta \kappa) E_{t} \sum_{j=0}^{\infty}(\beta \kappa)^{j} p_{t+j}^{*}
$$

The aggregate price level for the economy is then given by

$$
p_{t}=(1-\kappa) \hat{p}_{t}+\kappa p_{t-1} \text {. }
$$

Combining (3), (5), (7) and (8) the price level is given by

$$
p_{t}=\mu p_{t-1}+(1-\mu) m_{t}+\alpha_{1}\left(m_{t}-m_{t-1}\right)+\alpha_{2} \bar{m}
$$

where $\mu=\frac{1}{2}\left(1-v+\kappa v+\frac{\kappa(1-v)+v}{\beta \kappa}-\sqrt{\left(1-v+\kappa v+\frac{\kappa(1-v)+v}{\beta \kappa}\right)^{2}-\frac{4}{\beta}}\right)$,

$\alpha_{1}=\frac{\rho \beta \mu(1-\mu)}{1-\rho \beta \mu}$, and $\alpha_{2}=\frac{\beta \kappa(1-\mu)^{2}}{(1-\kappa)(1-\beta \kappa)(1-\rho \beta \mu) v}$.

The equilibrium time-dependent $\kappa$ may be approximated numerically. ${ }^{2}$

\footnotetext{
${ }^{2}$ See the appendix for details.
} 


\section{Predetermined Prices (PP)}

Now consider the alternative model where there is a fixed cost to drawing up a contract, which may entail a different price for each future period. Beginning the next period, the firm will again face a constant probability of adjusting its price contract.

Clearly the optimal price sequence for firm $i$ is

$$
\hat{p}_{t+j, t}(i)=E_{t} p_{t+j}^{*}
$$

while the aggregate price level for the economy is given by

$$
p_{t}=(1-\kappa) \sum_{j=0}^{\infty}(\kappa)^{j} E_{t-j} p_{t}^{*}
$$

The price level is the weighted sum of the desired price this period and previous periods' expectations of this desired price. Using equations (3), (5), (10), and (11),

$$
p_{t}=m_{t}-\sum_{j=0}^{\infty} \theta(j) u_{t-j},
$$

where $\theta(j)=\frac{\kappa^{j+1}\left(1-\rho^{j+1}\right)}{(1-\rho)\left[1-\left(1-\kappa^{j+1}\right)(1-v)\right]}$.

Substituting into (4), the expected loss with PP for firm $l$ who chooses frequency of price adjustment $\kappa_{l}$ is given by

$$
L^{C C}=\left(1-\beta \kappa_{l}\right) F+\frac{\beta \kappa_{l} v^{2} \sigma_{u}^{2}}{(1-\rho)^{2}}\left\{\sum_{j=0}^{\infty}\left(\beta \kappa_{l}\right)^{j}\left[\frac{1-\rho^{j+1}}{1-\left(1-\kappa^{j+1}\right)(1-v)}\right]^{2}\right\} .
$$

The equilibrium time-dependent $\kappa$ may then be solved numerically.,

\footnotetext{
${ }^{3}$ This loss function contains an infinite sum, where later terms are more heavily discounted. As a result, a finite approximation is adequate. For example, the value of $\kappa_{l}$ that minimizes the first 100 terms is identical to the one that minimizes the first 1000 terms to 4 decimal places.

${ }^{4}$ The Nash equilibrium $\kappa$ is given by $\kappa=\kappa_{l}$, where $\kappa_{l}$ minimizes (13). This is determined iteratively, resetting $\kappa=\kappa_{l}$ each iteration, until they converge. Note that the Nash equilibrium may be very different from the "optimal" value of $\kappa$ (that is, the value if the behavior of other price setters was not taken as
} 


\section{Section 3. A comparison of the FP and PP specifications.}

The optimal contract length may be solved numerically under both FP and PP.

The monetary process is calibrated to the U. S. economy using non-borrowed reserves, a widely used measure of an exogenous policy-determined monetary aggregate. Results over the 1959-2000 period are given in Table 1.

\begin{tabular}{|c|c|c|c|}
\hline \multicolumn{4}{|c|}{$\begin{array}{l}\text { Table 1: Estimated Non-borr } \\
\text { Dependent variable: } m_{t}-m_{t-1}\end{array}$} \\
\hline Variable & Coefficient & Standard Error & Significance \\
\hline Constant & 0.0058 & 0.0027 & 0.0352 \\
\hline$\left(m_{t-1}-m_{t-2}\right)$ & 0.2732 & 0.0750 & 0.0004 \\
\hline$\sigma_{u}^{2}$ & 0.0012 & & \\
\hline
\end{tabular}

Note that the constant is statistically significant. $\bar{m}, \rho$, and $\sigma_{u}^{2}$ are calibrated to the point estimates, and the optimal probability of price adjustment is then solved numerically for $\beta=0.985$. The results are given in Figure 1 , for different $v$ and $F$.

In all cases, the equilibrium $\kappa$ is less with FP than PP, implying longer average contract length in the latter case. This is not surprising, given that with PP, a price setter may adjust their prices over the life of a contract, while with FP, they cannot. Note also that as the level of real rigidity increases ( $v$ declines), the difference between the equilibrium $\kappa$ 's increases.

given). For example, for $F=0.002$ and $v=0.1$, the Nash equilibrium is $\kappa_{l}=0.483$, while the optimal value is $\kappa_{l}=0.694$. 


\section{Section 4. Conclusion}

Elsewhere, papers comparing fixed prices with predetermined prices have assumed that the frequency of re-setting price contracts is equal in either case. This note demonstrates that in equilibrium, the frequency of re-setting price contracts is greater with fixed prices than predetermined prices, for realistic parameter values.

\section{Appendix: Solving for $\kappa$ with Fixed Prices}

For a given $\kappa,(3),(5),(8)$, and (9) are jointly simulated. The optimal price set by firm $l$ with price adjustment probability $\kappa_{l}$ is

$$
\hat{p}_{t, l}=\phi_{1} p_{t-1}+\left(1-\phi_{1}\right) m_{t}+\phi_{2}\left(m_{t}-m_{t-1}\right)+\phi_{3} \bar{m}
$$

where $\phi_{1}=\frac{\left(1-\beta \kappa_{l}\right)(1-v) \mu}{1-\beta \kappa_{l} \mu}, \phi_{2}=\frac{\left(1-\beta \kappa_{l}\right)(1-v) \alpha_{1}+\beta \kappa_{l}\left[\phi_{1} \alpha_{1}+\left(1-\phi_{1} \rho\right)\right]}{1-\beta \kappa_{l} \rho}$, $\phi_{3}=(1-v) \alpha_{2}+\frac{\beta \kappa_{l}\left[\phi_{1} \alpha_{2}+\left(1-\phi_{1}\right)+\phi_{2}\right]}{1-\beta \kappa_{l}}$,

and the realized price in any given period may be computed as

$$
\bar{p}_{t, l}=\phi_{t, l} \hat{p}_{t, l}+\left(1-\phi_{t, l}\right) \bar{p}_{t-1, l}
$$

where $\phi_{t, l}$ is a random variable that takes the value 0 with probability $\kappa_{l}$ and 1 otherwise. Average loss over many possible shocks is given by

$$
L^{M C}=\frac{1}{L} \sum_{l=1}^{L} \sum_{t=t_{0}}^{T} \beta^{t-t_{0}}\left[\phi_{t, l} F+\left(\bar{p}_{t, l}-p_{t, l}^{*}\right)^{2}\right] .
$$

For suitably large $t_{0}$ (so that initial conditions do not matter), $T$, and $L$, a grid search may be used to determine the value of $\kappa_{l}$ that minimizes (A3). The simulation is then repeated using the estimated $\kappa_{l}$ as the new value of $\kappa$, until they converge (to the Nash equilibrium). The results presented here are for $t_{0}=100, T=200$, and $L=1000$. 


\section{References}

Ball, Laurence and David Romer (1990) "Real Rigidities and the Non-Neutrality of Money," Review of Economic Studies, 57(2), 183-203.

Calvo, Guillermo A. (1983) "Staggered Prices in a Utility-Maximizing Framework," Journal of Monetary Economics, 12(3), 383-98.

Devereux, Michael B. and James Yetman (2001) "Predetermined Prices and the Persistent Effects of Money on Output," Journal of Money, Credit, and Banking, Forthcoming.

Devereux, Michael B. and James Yetman (2002) "Menu Costs and the Long-Run OutputInflation Trade-off," Economics Letters, 76, 95-100.

Fischer, Stanley (1977) “Long-Term Contracts, Rational Expectations, and the Optimal Money Supply Rule,” Journal of Political Economy, 85(1), 191-205.

Mankiw, N. Gregory and Ricardo Reis (2001) "Sticky Information Versus Sticky Prices: A Proposal to Replace the New Keynesian Phillips Curve," Quarterly Journal of Economics, Forthcoming.

Romer, David (1990) “Staggered Price Setting with Endogenous Frequency of Adjustment," Economics Letters, 32, 205-210.

Romer, David (1996) Advanced Macroeconomics, McGraw-Hill.

Walsh, Carl (1998) Monetary Theory and Policy, MIT Press.

Woodford, Michael (2001) Interest and Prices, Chapter 3, http://www.princeton.edu/ woodford/chapter3.pdf 


\section{Figure 1: Equilibrium Frequency of Price Adjustment}
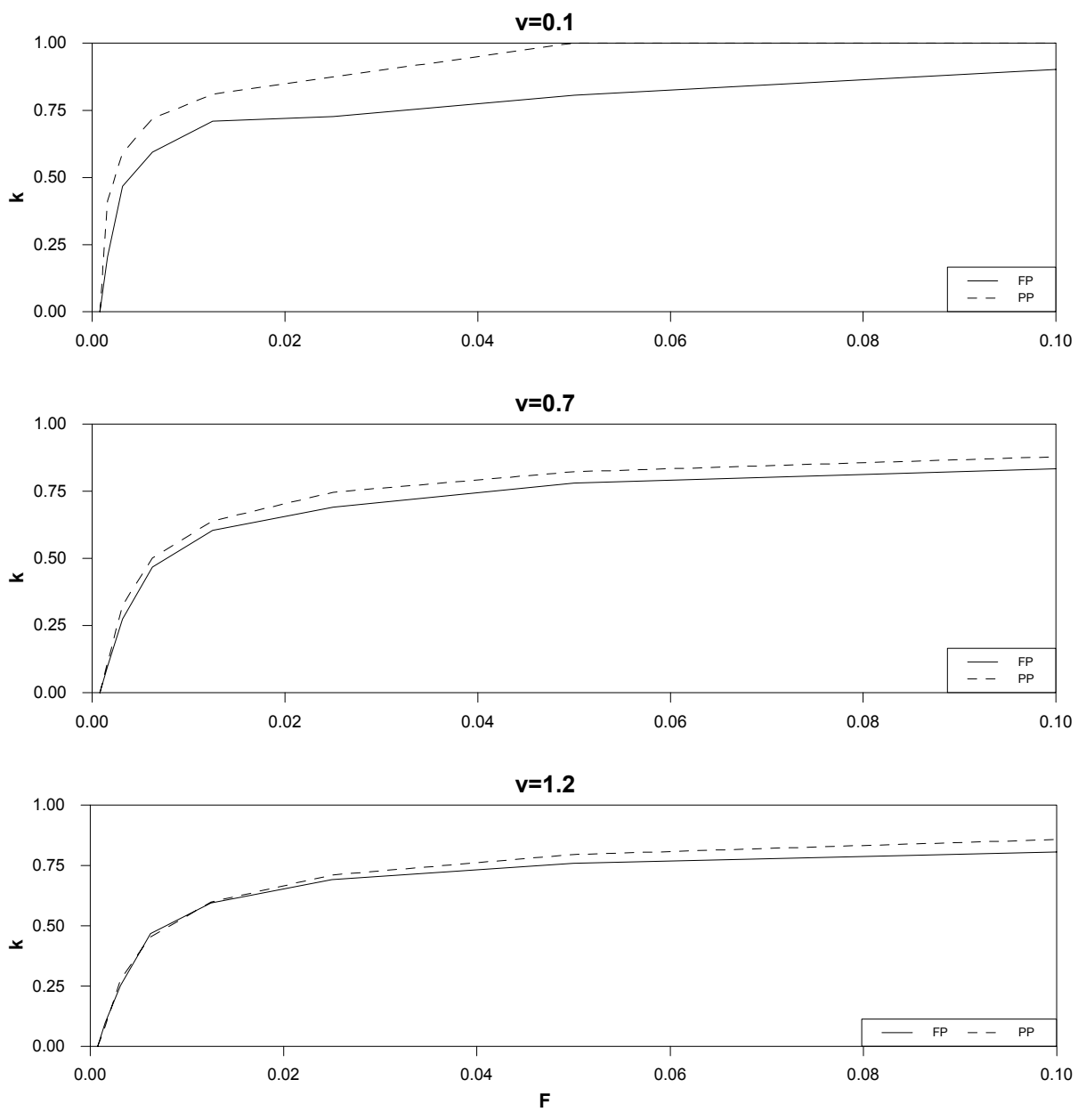